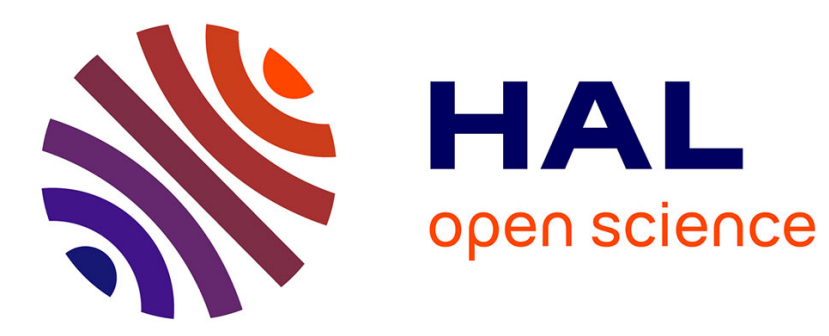

\title{
Intelligent Association Rules for Innovative SME Collaboration
}

\author{
Gulgun Kayakutlu, Irem Duzdar, Eunika Mercier-Laurent, Bahar Sennaroglu
}

\section{To cite this version:}

Gulgun Kayakutlu, Irem Duzdar, Eunika Mercier-Laurent, Bahar Sennaroglu. Intelligent Association Rules for Innovative SME Collaboration. 2nd IFIP International Workshop on Artificial Intelligence for Knowledge Management (AI4KM), Sep 2014, Warsaw, Poland. pp.150-164, 10.1007/978-3-31928868-0_9 . hal-01369809

\section{HAL Id: hal-01369809 \\ https://inria.hal.science/hal-01369809}

Submitted on 21 Sep 2016

HAL is a multi-disciplinary open access archive for the deposit and dissemination of scientific research documents, whether they are published or not. The documents may come from teaching and research institutions in France or abroad, or from public or private research centers.
L'archive ouverte pluridisciplinaire HAL, est destinée au dépôt et à la diffusion de documents scientifiques de niveau recherche, publiés ou non, émanant des établissements d'enseignement et de recherche français ou étrangers, des laboratoires publics ou privés. 


\title{
Intelligent Association Rules for Innovative SME Collaboration
}

\author{
Gulgun Kayakutlu ${ }^{1}$, Irem Duzdar ${ }^{2}$ and Eunika Mercier-Laurent ${ }^{3}$ \\ ${ }^{1}$ Industrial Engineering Dept., Istanbul Technical University, Macka 34367 Istanbul, Turkey \\ kayakutlu@itu.edu.tr \\ ${ }^{2}$ Industrial Engineering Dept., Istanbul Arel University, Tepekent 34537 Istanbul, Turkey \\ iremduzdar@arel.edu.tr \\ ${ }^{3}$ MODEME, Centre Magellan, Jean Moulin University, Lyon3, France \\ e.mercier-laurent@univ-lyon3.fr
}

\begin{abstract}
SMEs are encouraged to collaborate for research and innovation in order to survive in tough global competition. Even the technology SMEs with high knowledge capital have the fear to collaborate with other SMEs or bigger companies. This study aims to illuminate the preferences in customer, supplier and competitor collaboration within industry or inter industry. A survey is run on more than 110 companies and Machine Learning methods are used to define the association rules that will lead for success.
\end{abstract}

Keywords: Collaborative Innovation, Association Rules, SVM, SOM

\section{Introduction}

Knowledge based SMEs need to construct successful alliances in order to have sustainable business in a competitive environment. Global experiences with randomly chosen collaborators have shown failures that caused the fear of new collaborative work. Causes of failure based on the culture and the type of collaboration are studied [1]. The collaboration and creativity must be in the required skills to develop an effective knowledge management [2][3]. Abereijo et al. states that the innovation capability of any company depends on its capacity to combine the information assets and the experiences which can be found in the literature about the national innovation studies [4]. The approaches of owners to innovation, their tendencies and enthusiasm, and the social activities in the company, and dependence among workers are very important factors for effective knowledge management in SMEs [5]. Alliance in new product development has been the focus of industrial researchers [6] [7] [8].

One of the effective tools in knowledge management is becoming the association rules. There are many practices in technology firms and development projects for new products, but it is not used widely for cooperation of companies yet. Basically, to allocate the resources efficiently, the rules must be stated to regulate the information transfer. The well designed rules will be very effective to get benefits to SMEs which have limited capital and sources to continue the innovative operations. It can be seen in literature that the achievement measures and performance studies are useful for innovative collaboration. In business world, these criteria is trying to state a strategy for an individual company without employing the information coming from the knowledge assets of worldwide applications by decision makers.

This study aims to provide a pre-analysis of the path for successful alliances that will lead improvements in innovative power. Both qualitative and quantitative analysis of the SME alliances is realized to find the conditions causing failures and supporting the success in innovation. Support Vector Machine and Self Organized Maps are used to define the most frequent patterns that will give the support and confidence to identify the relationships. Association rules achieved will determine the optimal use of resources. 
This paper is so organized that the literature review will be given in the second section and the methodology definition will follow. The fourth section will be reserved for presenting the survey and the results. The conclusion will be given in the fifth and last section.

The implication of the study is generic enough to help any SME or research organization or large business to reduce risks in future alliances.

\section{Background}

The surveys on the interactions of the industrial stockholders had begun at the early 21st century. It can be seen easily that the expansive applications of outsourcing increases the importance of this matter.

More than 70 publications have been examined to have an understanding about the applications of the rules for cooperation between SMEs aimed at innovation. These studies implied that the main attention was on the various natures of interactions with SMEs and with Large Companies, either in an identified industry or different industries; either only for customers or both of the customers and suppliers. At the end of the detailed examination of this topic, the number of analyzed researches was 112, which were useful to classify on the base of methods.

The first research on Association Rule Mining and Methods is found in 1996 [9] trying to find the most frequent occurrences of events to support the linked processes. The research in the field followed the timeline shown in Figure 1.

The analysis in engineering branch shows that beginning from 2005, it takes its place increasingly reached 8 researches on annual average. The $25 \%$ of these researches were done in 2009 , and the maximum number is reached in this year.

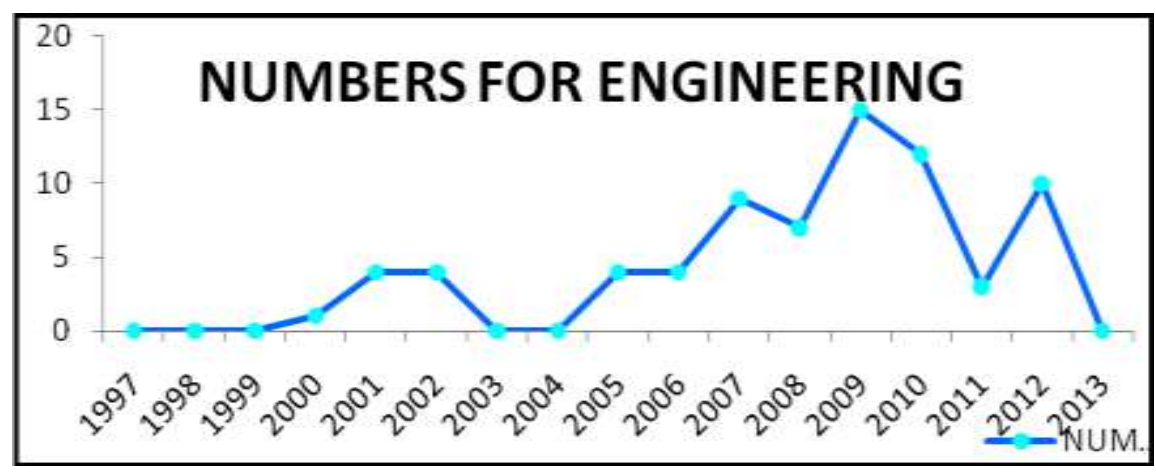

Fig. 1. Research timeline on Association Rules

The researches on association rule started in 1997 and the number of publications increased until 2007 , most of the studies were done about general subjects in this period. Then the general purpose studies reduced because the specification starts (Figure 2). The annual distribution of the published studies on 'Association Rule Methodology in Data Mining' is researched. The number of published applications about this subject increased until 2006. Between 2009-2011 years there is slight decrease, and then, last 3 years an increasing trend is observed. 


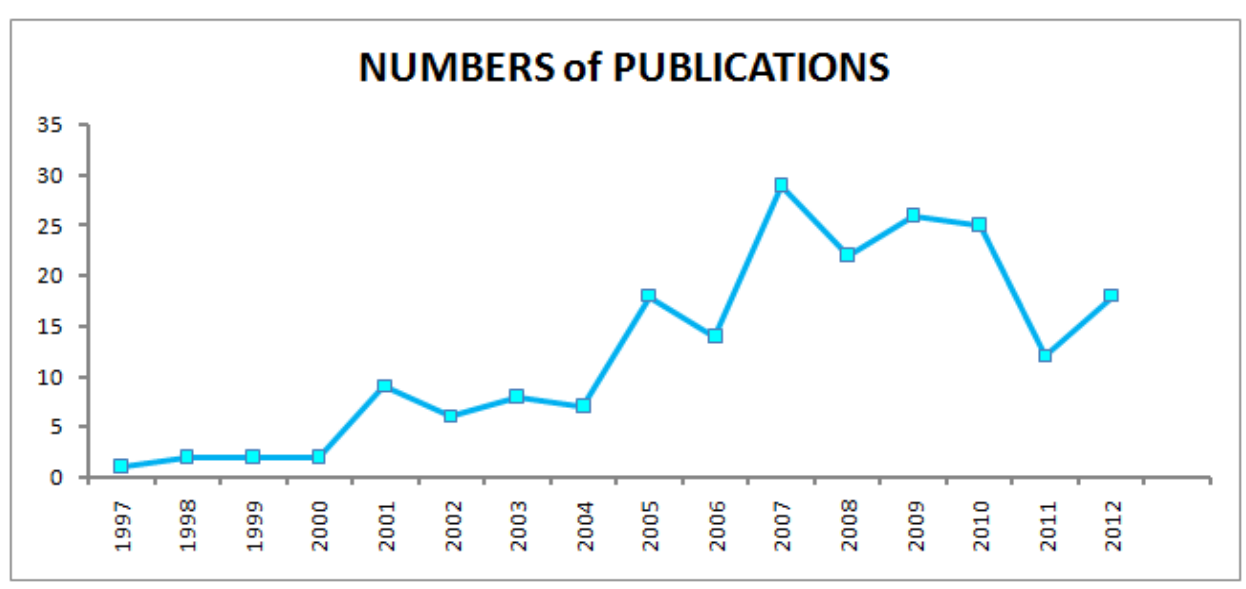

Fig. 2. Publication timeline on Association Rules

The usage of association rule in engineering is analyzed and the numbers of publications, the starting time seems 1999, but the reel beginning time is 2005. This matches the starting time of specialization on association rule studies.

Kakabadse et Al. showed that using improved communication and information technologies will improve the SME collaboration [1]. Also Post et al. showed the fact that SMEs would like to collaborate only for developing new products [10]. New product based collaboration has evolved fast [11]. Corporation and competition are found as flaming collaboration types that feed the SME improvements in innovation [12]. Association rules defined for the failure types have opened a new dimension for the research on failure of collaboration [13]. The first study on mining the SME innovation by Wang et $\mathrm{Al}$ has found some patterns for allocating the R\&D resources [14]. Suh \& Kim have detailed the R\&D collaboration in service industries detected the positive relations of technology and the product or process innovation [15]. Swarnkar et Al. analyzed when and how the collaboration strategies will be used in virtual organizations [16]. Wiltsey et al. claimed that extent, nature or impact of $\mathrm{R} \& \mathrm{D}$ programs are studied rarely. The interactions among the influences must be given in multiple levels and fidelity and changes must be observed in time [17]. Woodland \& Hutton introduced the social dimension on the collaborative success [18]. Both the fear issues and the success causes studied by Bouncken et al. defined technology influencers, sharing the knowledge and learning from the partner as the main influencers [6]. Bayo-Moriones et al. (2013) proposed that the effects of information and communication technology (ICT) has an indirect on the achievement of increasing the marketing capacity, profitability, and profit rates because of the advanced internal and external communication channels; just like the developed operational processes [19]. Sawers et al. concluded that the intrinsic advancement level of SMEs has inverse correlation with the enthusiasm for collaboration, where the effect of extrinsic level has direct correlation [20]. Rocha showed that empowering the business and the high level of competition at market area will lead to a larger SME industry [21]. Franco and Haase introduced various collaborating businesses and stated their general policies, and tendencies to cooperation together with their courses of action [22]. Antlová et al. insisted that the companies and their knowledge assets depending on the basic qualifications exhibit the developing businesses [23].

Knowledge management and data mining overviews [24] and Knowledge Management performance studies [25] realized recently do not show any association rule study for the collaborative innovation success and failure. 


\section{Methodologies}

\subsection{Association Rules}

Given a set of transactions, rules are defined that will exhibit that the occurrence of an item based on the occurrences of other items in the transaction. This is the association analysis. It is useful to explore the interesting relations, which are embedded in the huge data sets. These hidden interactions can be stated in the form of association rules [26]. The strength of an association rule is measured with its support and confidence values. Support shows the how often that rule is applicable to a given dataset. The Confidence is the occurrence frequency of the item in that transaction [9].

Support (s) is the fraction of transactions that contain an itemset

$$
s(X \rightarrow Y)=\frac{\sigma(X \cup Y)}{N}
$$

Confidence (c) measures how often items in $\mathrm{Y}$ appear in transactions that contain $\mathrm{X}$

$$
c(X \rightarrow Y)=\frac{\sigma(X \cup Y)}{\sigma(X)}
$$

The item set patterns are found in various methods which could be apriori or aposteriori. The overview of all the methods used in association srule studies are given in Figure 3.

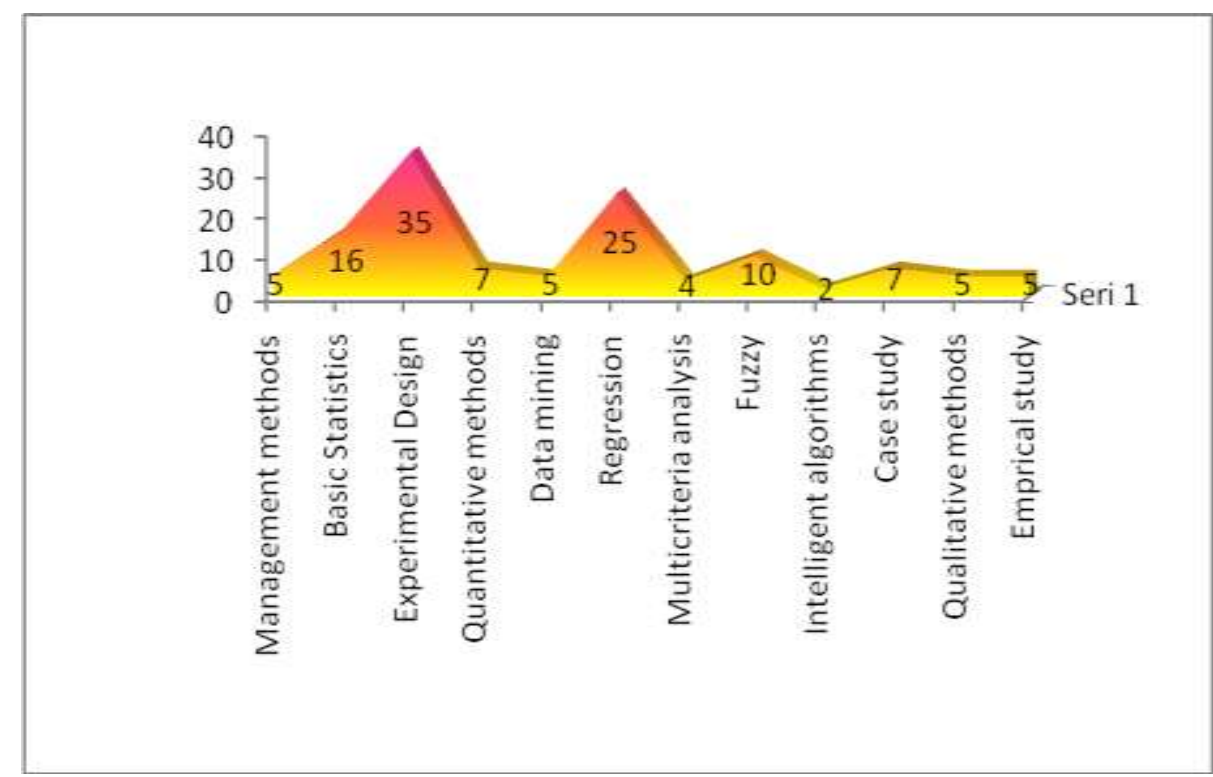

Fig. 3. Overview of Association rule techniques

\subsection{Support Vector Machines}

It is a machine learning technique, which is mainly introduced for classification in two classes [27] but further used in clustering [28].

It can be analyzed as an optimization problem as in Eq. 3 [29] relaxed with Lagrange multipliers in objective function as in equation 4 . 


$$
\begin{gathered}
\min z=\frac{1}{2}\|w\|^{2} \\
s . t . \\
r_{i}\left(w_{i} x_{i}+w_{0}\right) \geq 1
\end{gathered}
$$

Data is separated with a hyper-plane multiplied by -1 or +1 .

$$
L_{p}=\frac{1}{2}\|w\|^{2}-\sum_{i} \lambda_{i} r_{i}\left(w_{i} x_{i}+w_{0}\right)+\sum_{i} \lambda_{i}
$$

In 1990s Vapnik pioneered the development of support vector machines specifically for classification in two classes [27]. This method aims to develop an optimal hyper plane as a decision function using the maximum distance among two class vectors. Support Vector Using a Gaussian Kernel as defined in Eq. 5. will increase the reliability on dissimilarities [31].

$$
K\left(x, x_{i}\right)=\exp \left(-\frac{\left\|x-x_{i}\right\|^{2}}{2}\right)
$$

\subsection{Self Organized Maps}

Self-Organizing Map (SOM) is a widely used artificial neural network technique in clustering with unsupervised learning algorithm. This technique clusters according to the similarities to the input data [32]. SOMs structure the output with individual node similarity as well as cluster center distance. This technique is based on competitive learning, where the output nodes are made of the winning node activated by one input node. The output nodes would have scoring values using a function, most commonly Euclidean distance between the inputs and weights. For each input vector $\mathrm{x}$, and for each output node $\mathrm{j}$, the value $\mathrm{D}\left(\mathrm{w}_{\mathrm{j}}, \mathrm{x}_{\mathrm{n}}\right)$ of the scoring function. Euclidean distance function is shown in Eq. 6.

$$
D w_{j}, x_{n}=\left(w_{i j}-x_{n i}\right)^{2}
$$

The winning node therefore becomes the center of a neighborhood of excited nodes. In selforganizing maps, all nodes in the given neighborhood share competition. Therefore, even if the nodes in the output layer are not connected directly to the input layer, they tend to share common features, of the neighborhood [33]. The nodes in the neighborhood of the winning node participate in adaptation, which is, learning. The weights of these nodes are adjusted to improve the weights defined in Eq. 7., until a threshold is reached.

$$
w_{i j} \text { new }=w_{i j} \text { current }+\alpha x_{n i}-w_{i j} \text { current }
$$

In Eq 7. $\alpha$ is the learning rate. If it is necessary, the learning rate and neighborhood size are adjusted.

\section{Application}

A survey is run with the technology firms sited in Techno-parks of linked, 5 are about competences and 4 the technology choices. 130 firms responded but only 105 are included in the analysis. $14 \%$ of the companies were medium size and $37 \%$ of them were aged more than 10 years. They have chosen the type of collaboration among the SME and Big firms as well as among the customers, suppliers and competitors as shown in Figure 4. The reason for innovative collaboration is stated as shown in Figure 5 . 


\section{Preferred Collaborators}

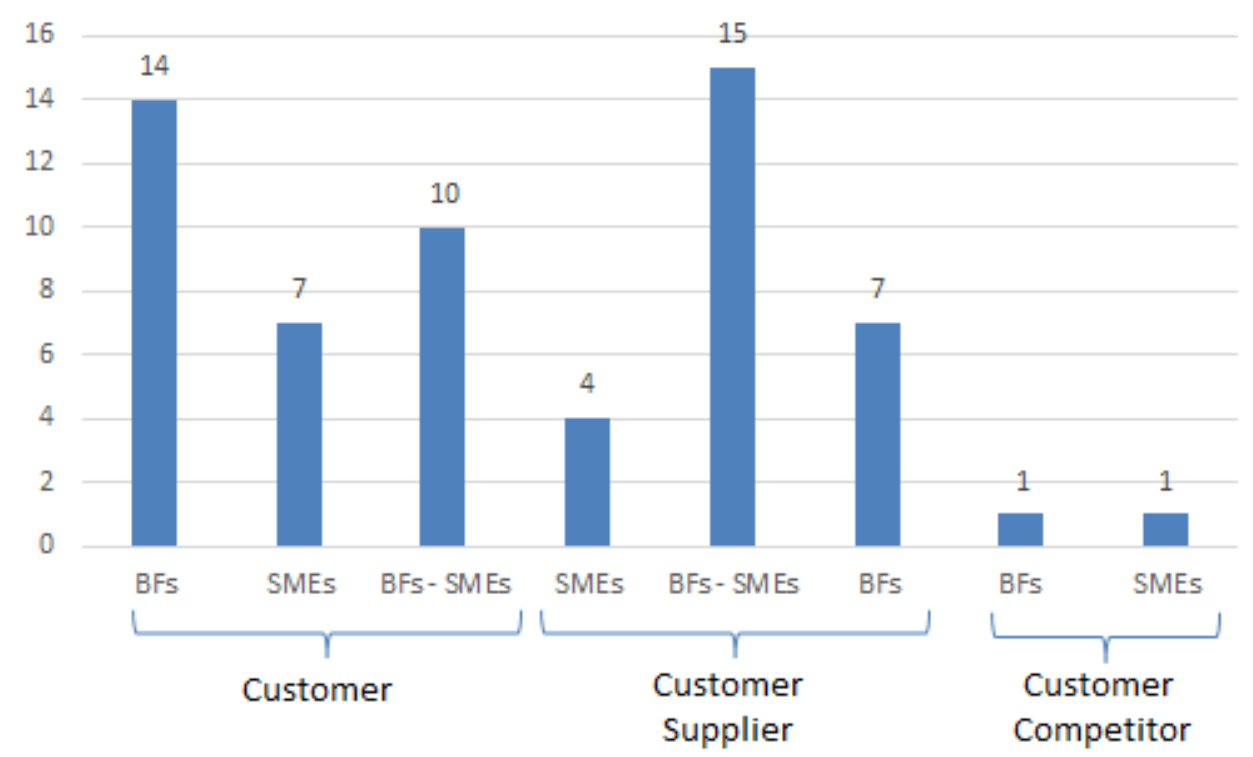

Fig. 4. Choice of collaboration according to size and relation

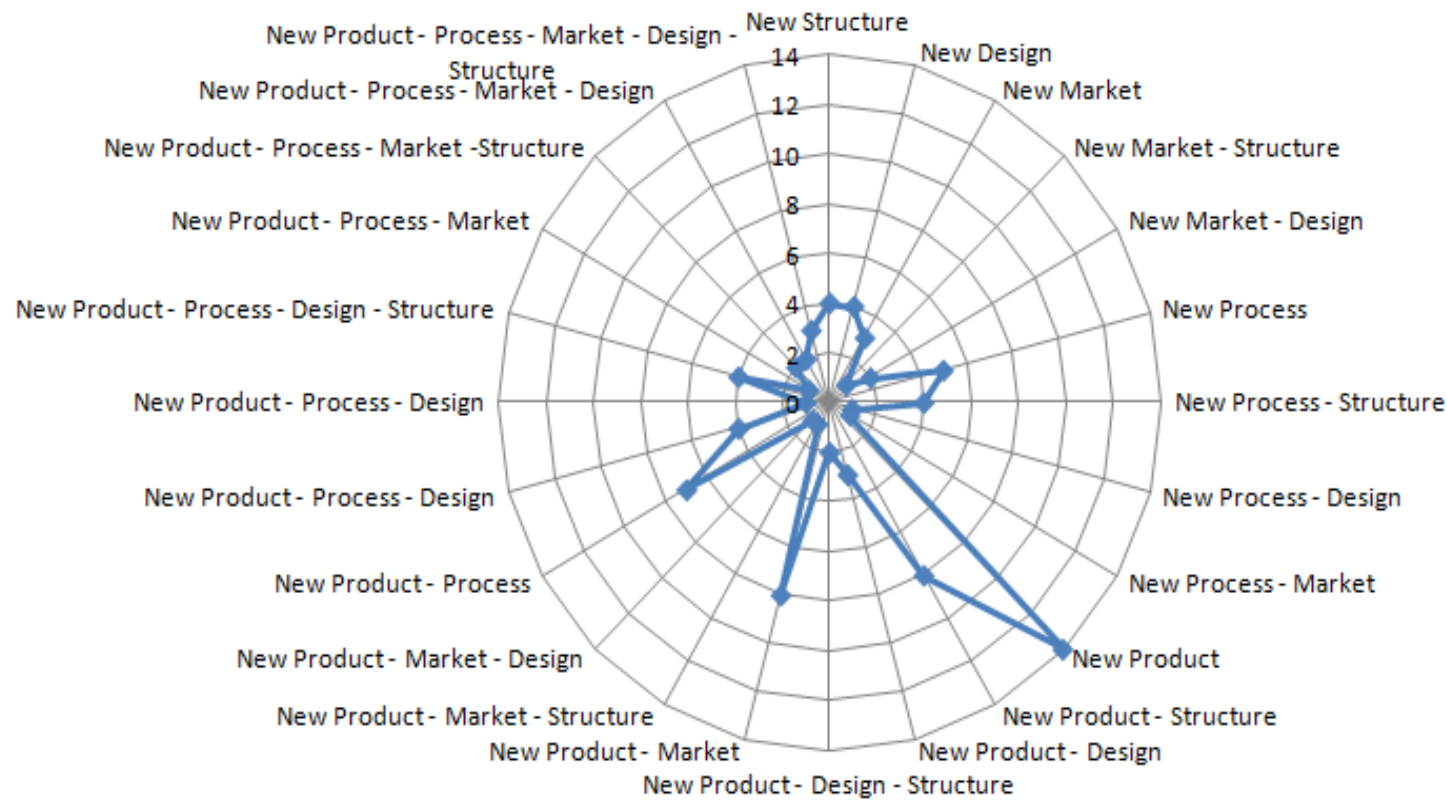

Fig. 5. Innovation causes in collaboration

When the choices of SMEs for innovation based collaboration is examined, the results are as follows. The number of responses is greater than 105, since this question gives the choice to select more than 1 reason for innovation based collaboration. Most of the SMEs are trying to develop a new product through innovation investments; total number is 61 . Secondly 35 firms are trying to have a new process at the end of the innovation tasks. There are 33 firms trying to find new design. The number of firms trying to reach new markets is 25 . The number of SMEs targeting the structural 
change is 23.19 of the firms have specified different goals. Just three of the firms aim all of the goals that are mentioned here.

SVM is applied to classify the collaboration made specifically for innovation, validated by Cronbach alpha, that resulted as more than 0.7. SOM is used to cluster those to show the supporting frequencies of choices. Then the cross tables are achieved as a basis for the association rules. The first achievement was micro companies would like all the collaborators to have innovation culture which is less important for the bigger companies. Some other samples of cross tables are given as below.

Table 1 gives the fact that majority of responders prefer for at least one collaborator to have design competence.

Table 1. Business Understanding and Design Competence

\begin{tabular}{|c|c|c|c|c|c|}
\hline \multirow[b]{2}{*}{ INNOV } & & & \multicolumn{3}{|c|}{ DESIGN } \\
\hline & & & All & $\begin{array}{l}\text { At least } \\
\text { one }\end{array}$ & $\begin{array}{c}\text { Neglig } \\
\mathrm{e}\end{array}$ \\
\hline \multirow[t]{2}{*}{$\begin{array}{l}\text { Collaboration } \\
\text { for others }\end{array}$} & Bus-Under & All & 4 & 14 & \\
\hline & & $\begin{array}{l}\text { At least } \\
\text { one }\end{array}$ & 2 & 15 & \\
\hline \multirow[t]{3}{*}{$\begin{array}{l}\text { Collaboration } \\
\text { for innovation }\end{array}$} & Bus-Under & All & 14 & 26 & 4 \\
\hline & & $\begin{array}{l}\text { At least } \\
\text { one }\end{array}$ & 7 & 13 & 2 \\
\hline & & Neglig. & 1 & 1 & 2 \\
\hline
\end{tabular}

In the firms collaborating for innovation for 1 to 3 years for the success of innovation it is necessary understanding the market requirements by all the firms together with the well-developed innovation culture.

Table 2. Age-Innovation Culture and Market Requirements Relation

\begin{tabular}{|c|c|c|c|c|c|}
\hline \multirow{2}{*}{\multicolumn{3}{|c|}{ COLLAB_Age }} & \multicolumn{3}{|c|}{ INNO_CULT } \\
\hline & & & \multirow{2}{*}{$\frac{\text { All }}{13}$} & \multirow{2}{*}{$\begin{array}{l}\begin{array}{c}\text { At least } \\
\text { one }\end{array} \\
8\end{array}$} & Neglige \\
\hline 0 & UNDERSTD_REQ & All & & & \\
\hline & & More than one & 6 & 6 & \\
\hline & & At least one & 0 & 1 & \\
\hline \multirow[t]{2}{*}{$<1$ year } & UNDERSTD_REQ & All & 9 & 1 & 0 \\
\hline & & More than one & 3 & 1 & 1 \\
\hline \multirow[t]{3}{*}{$1-3$ years } & UNDERSTD_REQ & All & 13 & 1 & \\
\hline & & More than one & 1 & 1 & \\
\hline & & At least one & 4 & 2 & \\
\hline \multirow[t]{3}{*}{ 3-5 years } & UNDERSTD_REQ & All & 6 & 1 & \\
\hline & & More than one & 3 & 2 & \\
\hline & & At least one & 0 & 1 & \\
\hline \multirow[t]{3}{*}{$>5$} & UNDERSTD_REQ & All & 8 & 2 & 0 \\
\hline & & More than one & 3 & 2 & 2 \\
\hline & & At least one & & & \\
\hline
\end{tabular}




\section{Results}

The Reliability analyzes have been done on the results of the questionnaires, the Cornbach's Alpha value is 0.602 ; this value is in the acceptable range. In the logistic regression model, the determined significance level is 0.100 . The values of attributes of innovation are neglected, since they are greater than 0.100. Innovation related criteria in this study have no significance based on firm size and collaborator types of these firms. In other words, firms care the technological features but ignore the innovative attributes. In the table below, the significance values are shown for the other 3 attributes and the results of analyzes for features of the questions. The significance values less than 0.100 are used here (Figure 6).

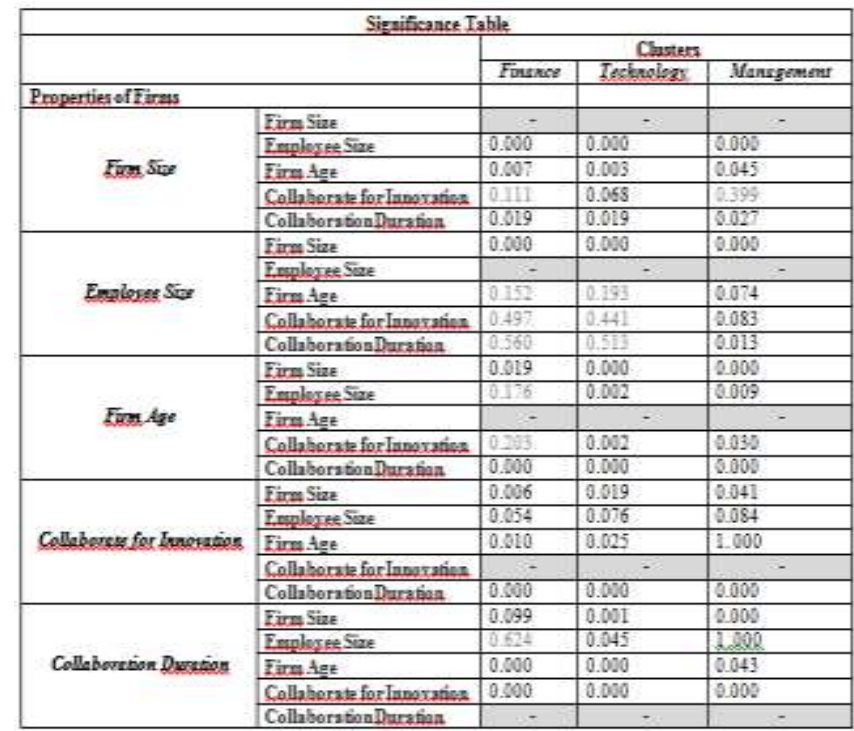

Fig. 6. Significance values for each clusters based on demographic properties

After the multinomial logistic regression analysis coefficients for all attributes are obtained. The statistically significant attributes are used. Coefficients of financially related criteria are shown in Figure 7.

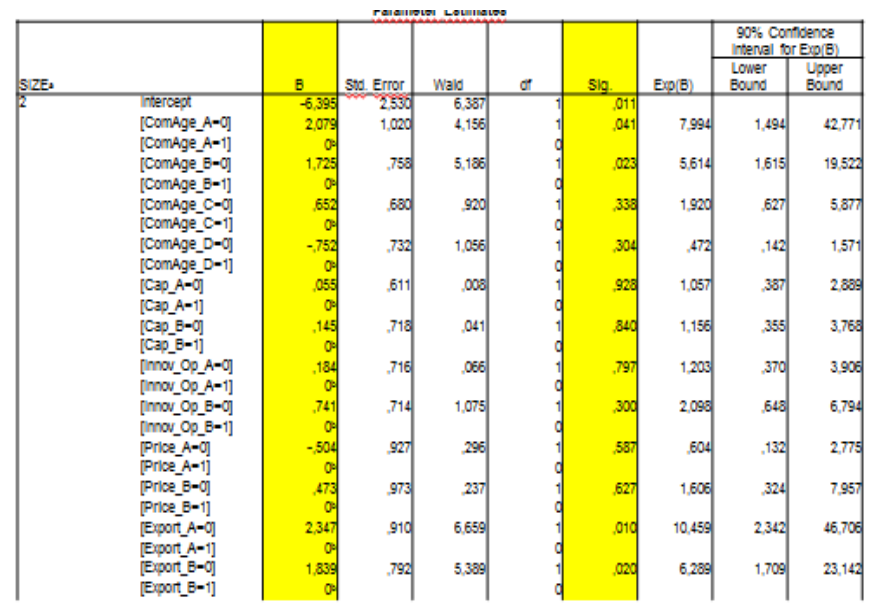

Fig. 7. Regression Coefficients \& Significancies 
The cross relation tables have been constructed to define the rules obtained from the model.

\section{Finance Related Criteria :}

\section{RULE 1:}

IF

$($ Firm Size $=$ "Micro" AND Firm Age $\leq$ "1")

\section{THEN}

(Innovation operation expenditure $=$ "proportionally shared" AND Price $=$ "important")

\section{MEANING:}

$\checkmark$ Preferences for the initiating micro SMEs emphasize the innovation operation expenditures according to the collaborator sharings and market value (price) of the innovated product (Figure 8).

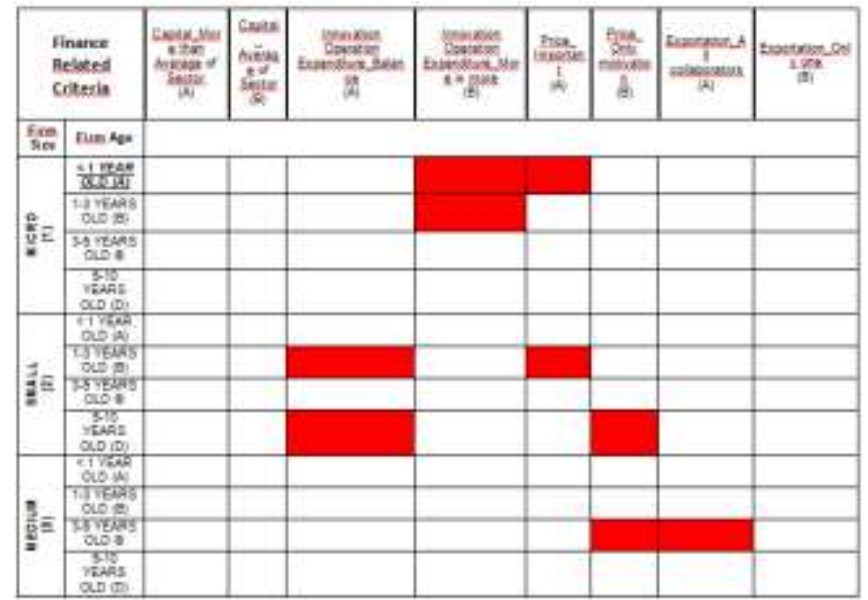

Fig. 8. Cross - relations Table: Firm Size - Firm Age - Finance Related Criteria

\section{RULE 2:}

IF

$($ Firm Size $=$ "Small" AND Collaborate = "Large Firms")

\section{THEN}

$($ Capital $=$ "more than average" AND Exportation facilities = "only one firm")

\section{MEANING:}

$\checkmark$ Small SMEs emphasize that capital of the collaborators are to be more than the sector average and exportation facilities are done by only one collaborator for innovation (Figure 9). 


\begin{tabular}{|c|c|c|c|c|c|c|c|c|c|}
\hline \multicolumn{2}{|c|}{$\begin{array}{c}\text { Finance related } \\
\text { Criteria }\end{array}$} & \multirow{2}{*}{$\begin{array}{l}\text { Capital } \\
\text { Mers } \\
\text { Then } \\
\text { Average } \\
\text { of Section }\end{array}$} & \multirow[t]{2}{*}{$\begin{array}{l}\text { Copital } \\
\text { exeraps } \\
\text { of } \\
\text { sector }\end{array}$} & \multirow{2}{*}{$\begin{array}{l}\text { Innovallon } \\
\text { Operation } \\
\text { Expesadue } \\
\text { Ealonce }\end{array}$} & \multirow{2}{*}{$\begin{array}{c}\text { Innoviaton } \\
\text { Operation } \\
\text { Expondeven } \\
\text { Mors is } \\
\text { more }\end{array}$} & \multirow[t]{2}{*}{$\begin{array}{l}\text { Price- } \\
\text { important }\end{array}$} & \multirow[t]{2}{*}{$\begin{array}{c}\text { Price } \\
\text { Only } \\
\text { notivation }\end{array}$} & \multirow[t]{2}{*}{$\begin{array}{c}\text { Expertide } \\
\text { nuAl } \\
\text { collet }\end{array}$} & \multirow[t]{2}{*}{$\begin{array}{l}\text { Expoetation } \\
\text { - Oaly ons }\end{array}$} \\
\hline cols & Firm Sate & & & & & & & & \\
\hline \multirow{3}{*}{$\frac{\text { Cust }}{\text {-LF: }}$} & Micro & & & & & & & & \\
\hline & $5 \mathrm{mali}$ & & & & & & & & \\
\hline & Medvem & & & & & & & & \\
\hline \multirow{3}{*}{$\begin{array}{l}\text { Cust } \\
\text { suEs }\end{array}$} & Mero & & & & & & & & \\
\hline & Smait & & & & & & & & \\
\hline & Mediem & & & & & & & & \\
\hline \multirow{3}{*}{$\begin{array}{l}\text { Cunt- } \\
\text { Supp } \\
\text {-LFs }\end{array}$} & Miera & & & & & & & & \\
\hline & Smail & & & & & & & & \\
\hline & Medsaim & & & & & & & & \\
\hline \multirow{3}{*}{$\begin{array}{l}\text { Cust: } \\
\text { Supp } \\
\text { suts } \\
\text {-LFx }\end{array}$} & Miero & & & & & & & & \\
\hline & Small & & & & & & & & \\
\hline & Medium & & & & & & & & \\
\hline \multirow{3}{*}{ Cast } & Miers & & & & & & & & \\
\hline & Smail & & & & & & & & \\
\hline & Medem & & & & & & & & \\
\hline \multirow{3}{*}{$F_{2}$} & Micro & & & & & & & & \\
\hline & Smnill & & & & & & & & \\
\hline & Medvem & & & & & & & & \\
\hline \multirow{3}{*}{$\begin{array}{l}\text { Cugs: } \\
\text { Supp- } \\
\text { sues. }\end{array}$} & Micro & & & & & & & & \\
\hline & Smal & & & & & & & & \\
\hline & Medion & & & & & & & & \\
\hline
\end{tabular}

Fig. 9. Cross - relations Table: Collaboration - Firm Size - Finance Related Criteria

\section{RULE 3:}

IF

(Firm Age $=$ "> 10 years old" AND Collaboration Duration = "3-5 years")

\section{THEN}

$($ Capital $=$ "more than average" AND Price = "motivation")

\section{MEANING:}

$\checkmark 10$ years (and more) old SMEs emphasize capital of the collaborators have to be more than the sector average whereas market value (price) of the innovated product is only a motivation.

\section{Technology Related Criteria :}

IF

$($ Firm Size $=$ "Small" AND Firm Age $=$ "3-5 years old")

THEN

$($ Connectivity = "All possible ways" AND Change Management $=$ "All Collaborators")

\section{MEANING:}

$\checkmark$ SMEs with age 5 to 10 years old emphasize change management is to be applied by all collaborators and use all possible connectivity possibilities.

\begin{tabular}{|c|c|c|c|c|c|c|c|c|c|}
\hline \multicolumn{2}{|c|}{$\begin{array}{l}\text { Technology Related } \\
\text { Criteria }\end{array}$} & \multirow[t]{2}{*}{$\begin{array}{c}\text { MIS_ } \\
\text { Leastone }\end{array}$} & \multirow[t]{2}{*}{ MIS_All } & \multirow[t]{2}{*}{$\begin{array}{l}\text { Comm, If } \\
\text { tech exist }\end{array}$} & \multirow[t]{2}{*}{$\begin{array}{l}\text { All } \\
\text { teckh }\end{array}$} & \multirow[t]{2}{*}{$\begin{array}{l}\text { ChngaMng } \\
\text { individual }\end{array}$} & \multirow[t]{2}{*}{$\begin{array}{l}\text { ChnolWha } \\
\text { Together }\end{array}$} & \multirow[t]{2}{*}{$\begin{array}{l}\text { Connect } \\
\text { - enly } \\
\text { ene type }\end{array}$} & \multirow[t]{2}{*}{$\begin{array}{l}\text { Connect } \\
\text { All } \\
\text { ways }\end{array}$} \\
\hline COLL & Firm Size & & & & & & & & \\
\hline \multirow{3}{*}{ Cust-LEs } & Micro & & & & & & & & \\
\hline & Small & & & & & & & & \\
\hline & Medium & & & & & & & & \\
\hline \multirow{3}{*}{$\begin{array}{l}\text { Cust- } \\
\text { SMES }\end{array}$} & Micro & & & & & & & & \\
\hline & Small & & & & & & & & \\
\hline & Medium & & & & & & & & \\
\hline
\end{tabular}

Fig. 10. Cross - relations Table: Collaboration - Firm Size - Technological Criteria 
Figure 10 shows the cross - relations between collaborator type (customer - supplier - SMEs - large firms) and firms' size for the technology related criteria. Also this mentioned model makes sense statistically significant as a result of the logistic regression analysis.

\section{RULE 2:}

\section{IF}

$($ Firm Size $=$ "Small" years old" AND Collaborate = "Customers" and "LFs")

\section{THEN}

(Communication technologies $=$ "All opportunities" AND Change Management $=$ "Individual")

\section{MEANING:}

$\checkmark$ Small SMEs who are collaborating with the customers which are large firms (LFs) emphasize usage of all communication technologies opportunities and change management is can be individual choice (Figure 9 ).

\section{Management Related Criteria :}

\section{RULE 1:}

\section{IF}

$($ Firm Size $=$ "Medium" AND Firm Age $=$ "5-10 years old" $)$

\section{THEN}

$($ Professionalism $=$ "Motivation" AND Organizational Structure $=$ "Effective" AND Cooperation \& Coordination $=$ "All" AND Leadership $=$ "Only one")

\section{MEANING:}

$\checkmark$ Medium size SMEs of age 5-10 years prefer to collaborate with companies which have effective organizational structure with both cooperation and coordination attitude; in the collaboration a single leader is preferred and professionalism can be taken only as the motivator.

\section{RULE 2:}

\section{IF}

$($ Firm Size $=$ "Micro" AND Collaborate $=$ "Customers" and "SMEs")

\section{THEN}

$($ Professionalism $=$ "All” AND Business Experience $=$ "All” AND Leadership = "All")

\section{MEANING:}

$\checkmark$ The micro SMEs collaborating with the customers emphasize professionalism, business experience for the problem solving and they prefer all the collaborators to have the leadership features. 


\section{Conclusion}

This study investigates the most preferred conditions for a successful collaboration for innovative SMEs. SVM and SOM are used to construct the basis for creating the association rules. As the result of a survey in Turkey, there are hundreds of relations depicted in the analysis.

The achievements are interesting enough to show that the technology companies are confused in differentiating the technology and innovation concepts. It was interesting to observe micro and young companies not willing to collaborate with the big and overwhelming companies. Everybody asks for full communication technology, but only small SME with 5-10 years of experience ask for the collaborators to have effective organization and full professionalism.

The validation by logistic regression on the same data is in process. All the results achieved using logistic regression will be cross-validated with machine learning application results. Future survey will be aiming to improve the innovation concept of the technology firms in detail.

\section{References}

1. Kakabadse, N.K.; Kakabadse, A.; Ahmed, P.K.; Kouzmin, "The ASP phenomenon: an example of solution innovation that liberates organization from technology or captures it?," Eur. J. Innov. Manag., vol. 7, no. 2, pp. 113-127, 2004.

2. B.J Horak, "Dealing with human factors and managing change in knowledge management: a phased approach", Topics in Health Information Management, Vol. 21 No. 3, pp. 8-17, 2001

3. S. Yahya and W.K. Goh, "Managing human resources toward achieving knowledge management", Journal of Knowledge Management, Vol. 6 No. 5, pp. 457-68, 2002.

4. I.O. Abereijo, S.A. Adegbite, M.O. Ilori, A.A. Adeniyi, and H.A.Aderemi, "Technological innovation sources and institutional supports for manufacturing small and medium enterprises in Nigeria", Journal of Technology Management \& Innovation, Vol. 4 No. 2, pp. 82-89, 2009.

5. J. CN Wee and A. YK. Chua, "The peculiarities of knowledge management processes in SMEs: the case of Singapore" Journal of Knowledge Management 17.6: 958-972, 2013.

6. S. Bouncken, Ricarda B.; Kraus, "Innovation in knowledge-intensive industries: The double-edged sword of coopetition,” J. Bus. Res., vol. 66, no. 10, pp. 2060-2070, 2013.

7. D. R. Gnyawali and B. R. Park, "Co-opetition and technological innovation in small and medium sized enterprizes A Multilevel Conceptual Model,” J. Small Bus. Manag., vol. 47, no. 3, pp. 308-330, 2009.

8. R. Narula, "R\&D collaboration by SMEs: New opportunities and limitations in the face of globalisation," Technovation, vol. 24, no. 2, pp. 153-161, 2004.

9. R. Agrawal, "Parallel mining of association rules," IEE Tran. Knowl. Data Eng., vol. 8, no. 6, pp. 962-969, 1996.

10. G. J. J. Post, L. Hop, and J. E. van Aken, "Indicators for establishing SME product development networks," J. Sci. Ind. Res., vol. 60, no. 3, pp. 264-276, 2001.

11. R. Narula, "R\&D collaboration by SMEs: New opportunities and limitations in the face of globalisation," Technovation, vol. 24, no. 2, pp. 153-161, 2004.

12. D. R. Gnyawali and B. R. Park, "Co-opetition and technological innovation in small and medium sized enterprizes A Multilevel Conceptual Model,” J. Small Bus. Manag., vol. 47, no. 3, pp. 308-330, 2009.

13. Z. Z. Z. Zheng, Z. L. Z. Lan, B. H. Park, and A. Geist, "System log pre-processing to improve failure prediction,” 2009 IEEE/IFIP Int. Conf. Dependable Syst. Networks, 2009.

14. C. H. Wang, Y. C. Chin, and G. H. Tzeng, "Mining the R\&D innovation performance processes for hightech firms based on rough set theory," Technovation, vol. 30, pp. 447-458, 2010. 
15. Y. Suh and M.-S. Kim, "Effects of SME collaboration on R\&D in the service sector in open innovation," Innovation: Management, Policy \& Practice, vol. 14, no. 3. pp. 349-362, 2012.

16. R. Swarnkar, A. K. Choudhary, J. A. Harding, B. P. Das, and R. I. Young, "A framework for collaboration moderator services to support knowledge based collaboration," Journal of Intelligent Manufacturing, vol. 23. pp. 2003-2023, 2012.

17. S. Wiltsey Stirman, J. Kimberly, N. Cook, A. Calloway, F. Castro, and M. Charns, "The sustainability of new programs and innovations: a review of the empirical literature and recommendations for future research," Implementation Science, vol. 7. p. 17, 2012.

18. R. H. Woodland and M. S. Hutton, "Evaluating Organizational Collaborations: Suggested Entry Points and Strategies," American Journal of Evaluation, vol. 33. pp. 366-383, 2012.

19. A. Bayo-Moriones, , M. Billón, and F. Lera-López. "Perceived performance effects of ICT in manufacturing SMEs" Industrial Management \& Data Systems 113.1: 117-135, 2013.

20. J.L. Sawers, M. W. Pretorius and L. AG. Oerlemans. "Safeguarding SMEs dynamic capabilities in technology innovative SME-large company partnerships in South Africa" Technovation 28.4: 171-182, 2008.

21. E.A.G. Rocha, "The impact of the business environment on the size of the micro, small and medium enterprise sector; preliminary findings from a cross-country comparison" Procedia Economics and Finance 4, 335-349, 2012.

22. M. Franco and H. Haase, "Interfirm alliances: a taxonomy for SMEs."Long Range Planning, 2013.

23. K. Antlová, L. Popelínsky, and J. Tandler, "Long term growth of SME from the view of ICT competencies and web presentations" E+ M Ekonomie a management 1: 125-138, 2011.

24. H. H. Tsai, "Knowledge management vs. data mining: Research trend, forecast and citation approach," Expert Syst. Appl., vol. 40, no. 8, pp. 3160-3173, 2013.

25. I. B. Tae Hun Kim, Jae-Nam Lee, Jae Uk Chun, "Understanding the effect of knowledge management strategies on knowledge management performance: A contingency perspective,” Inf. Manag., vol. 51, pp. 398416,2014

26. J. Jackson, "Data mining: A conceptual overview," Commun. Assoc. Inf. Syst., vol. 8, pp. 267-296, 2002.

27. C.Cortes and V. Vapnik, "Support Vector Networks," Mach. Learn., vol. 20, pp. 273-297, 1995.

28. T. Finley and T. Joachims, "Supervised clustering with support vector machines," in Proceedings of the 22nd International Conference on Machine learning (ICML), 2005, pp. 217-224.

29. S. Haykin, Neural Networks: A Comprehensive Foundation, Prentice-Hall, New Jersey, 1999.

30. E. Alpaydın, Machine Learning, Massachusetts Institute of Technology, USA, 2004.

31. V. Cherkassky, Y. Ma, Practical selection of SVM parameters and noise estimation for SVM regression, Neural Networks 17 (2004) 113-126.

32. E. Leopold, M. May, and G. Paßß, "Data Mining and Text Mining for Science \& Technology Research," in Handbook of Quantitative Science and Technology Research - The Use of Publication and Patent Statistics in Studies of S\&T Systems, H. F. Moed, W. Glänzel, and U. Schmoch, Eds. Springer, 2004, pp. 187-213.

33. Larose, D.T. 2005. Discovering Knowledge in Data: An Introduction to Data Mining. New Jersey: John Wiley \& Sons, Inc. 